\title{
Update on the treatment of metastatic clear cell and non-clear cell renal cell carcinoma
}

\author{
Kevin $Y X^{1}$ and Shenhong $W^{2,3^{*}}$
}

\begin{abstract}
The advent of new knowledge surrounding the molecular pathology of renal-cell carcinoma (RCC) has culminated in a number of emerging targeted therapies. In just the last year, several new studies have been able to translate our understanding of tumor biology into significantly improved outcomes in patients with advanced RCC. The objective of this review is to describe new developments in targeted treatments and immunotherapies for patients with both clear-cell and non-clear cell metastatic RCC following the 2014 American Society of Clinical Oncology (ASCO) annual conference. We will discuss new applications of anti-VGF agents and PD-1 inhibitors in order to shed light on emerging avenues of RCC treatment that show considerable promise.
\end{abstract}

Keywords: Renal cell carcinoma, Clear cell, Non-clear cell, PD-1, Tyrosine kinase inhibitor

\section{Introduction}

With the development of multiple anti-VEGF (vascular endothelial growth factor) agents and mTOR (mammalian target of rapamycin) inhibitors, we have seen significant progress over the last few years in targeted therapies for treating renal cell carcinoma (RCC). While these targeted therapies were largely tested in patients with the more common clear cell RCC (ccRCC), recent studies have begun to investigate the efficacy of targeted therapy in the much less common, non-clear cell RCC (nccRCC). In addition, a number of new studies have, for the first time, examined the activity of new immunotherapies in treating ccRCC. In this article, we performed a brief review of recent studies on the treatment of RCC with an update from 2014 annual ASCO meeting.

\section{Review}

RCCs are characterized by a vast array of different histological and cytogenetic signatures. Of approximately 64,000 cancers of the kidney every year [1], 80\% are clear cell renal cell carcinoma (ccRCC) and $20 \%$ are non-clear cell renal cell carcinoma (nccRCC) subtypes.

VEGF signaling plays a significant role in tumorigenesis in light of its role in angiogenesis, vascular permeability,

\footnotetext{
* Correspondence: shenhong.wu@stonybrookmedicine.edu

${ }^{2}$ Division of Hematology/Oncology, Department of Medicine, Stony Brook University School of Medicine, Room: HSC 15-053E, Stony Brook, NY, USA

${ }^{3}$ Northport VA Medical Center, Northport, NY, USA

Full list of author information is available at the end of the article
}

and cancer stem cell development. It is important to note that the more common ccRCC has often been tied to the occurrence of von Hippel-Lindau (VHL) mutations implicated in VEGF signaling deregulation [2]. Such mutations have been found to contribute to an accumulation of transcription factor HIF1 $\alpha$ (hypoxia-inducible factor 1-alpha) and, consequently, increased levels of VEGF and other growth factors. Because the up-regulation of VEGF activity has corresponded to the uncontrolled modulation of the hypoxic response, multiple agents (e.g., sorafenib, sunitinib, bevacizumab, pazopanib, axitinib, temsirolimus, everolimus) have been identified as abrogators of VEGFmediated signaling $[3,4]$. These therapeutic agents operate through a variety of mechanisms, many of which abrogate specific components of the VEGF signaling (TKIs for VEGFR, bevacizumab for VEGF).

In addition to VEGF pathway deregulation, mTOR kinase is a well-known contributor to tumorigenesis. Given that a number of downstream mTOR effectors regulating angiogenesis, metabolism, and cell growth have been found to be deregulated in cancers, various targeted therapies such as temsirolimus and everolimus have been developed to hinder mTOR signaling. These two mTOR signaling-based therapies will be discussed in upcoming paragraphs.

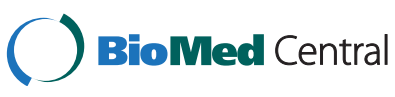

(c) 2015 Xu and Wu; licensee BioMed Central. This is an Open Access article distributed under the terms of the Creative Commons Attribution License (http://creativecommons.org/licenses/by/4.0), which permits unrestricted use, distribution, and reproduction in any medium, provided the original work is properly credited. The Creative Commons Public Domain Dedication waiver (http://creativecommons.org/publicdomain/zero/1.0/) applies to the data made available in this article, unless otherwise stated. 


\section{Targeted therapy for RCC with bone metastases}

In recent years, a considerable number of tyrosinekinase inhibitors (TKIs) have been developed that seek to target VEGF signaling in ccRCC. Among the most prevalent of such targeted ccRCC therapies are TKIs such as pazopanib, sorafenib, and axitinib, which have been found to lead to significantly improved outcomes for metastatic renal cell carcinoma (mRCC) patients. For instance, bevacizumab, a humanized anti-VEGF antibody, was found in phase III randomized controlled trials (RCTs) to contribute to significant increases in progression-free survival in mRCC patients who had used interferon alfa as first-line treatment [5]. An oral angiogenesis inhibitor (pazopanib) targeting VEGFR, PDGFR (platelet-derived growth factor receptor), and the c-kit tyrosine kinase were found to demonstrate significant improvements in progression-free survival and tumor response in both treatment-naive and pre-treated patients with mRCC [6]. Paralleling pazopanib's effects, sorafenib (an oral multikinase inhibitor of VEGF receptors, platelet-derived growth factor receptors, and Raf kinases) was found in a phase III RCT to contribute to significantly longer median progression-free survival in mRCC patients compared to placebo [7]. Building off the trial's promising results, a more recent phase III RCT revealed that the second-generation inhibitor of VEGF receptors, axitinib, culminated in even longer progression-free survival (PFS) than sorafenib, supporting this VEGFR inhibitor's suitability as a second-line therapies for mRCC [8]. Besides VEGF inhibition, mTOR inhibitors such as temsirolimus (an inhibitor of rapamycin kinase) have also been found to significantly improve overall survival (OS) among mRCC patients with poor prognosis [9].

While the efficacy of TKIs in treating metastatic ccRCC has been well established, a new body of research has sought to examine the therapeutic value of TKIs in treating mRCC patients with bone metastases (BM), long considered one of the most destructive of mRCC complications. Despite the high prevalence of BM, therapies for BM management have been very limited in advanced renal cell carcinoma in light of the poorer prognosis that patients with $\mathrm{BM}$ have relative to those who do not have BM. In a retrospective review of 375 mRCC patients presented in this year's ASCO annual meeting, the median survival of BM patients using TKI was found to be significantly longer than those who had not used TKIs [22 months (95\% CI: 17-25) vs. 14 months (95\% CI: 10-19), p <0.01] [10]. However, mRCC patients with BM who were treated with TKIs were observed to have a similar median OS as patients without BM $(p=0.66)$. It necessitates emphasis that this study was limited by its retrospective nature, lack of randomization or blinding, and accuracy of documentation. Future prospective clinical trials may be warranted to better understand the interplay between different TKIs and their efficacy on mRCC patients with BM.

\section{New immunotherapy (PD-1 inhibitors) for clear cell RCC}

Besides targeted therapies, immunotherapies seeking to break tumor tolerance are another area of interest in the RCC research community. Instead of directly targeting malignant cells and stroma, immunotherapies work to up-regulate the host immune response in order to destroy neoplastic cells that escape immune recognition.

An immune signaling mechanism of particular interest to cancer clinicians is the PD-1 pathway. A potent immune checkpoint receptor, programmed death-1 (PD-1) is a cell-surface glycoprotein on $\mathrm{T}$ cells, $\mathrm{B}$ cells, and macrophages that inhibits their activation. In recent years, therapeutic agents inhibiting the PD-1 pathway and increasing the strength of the host's anti-tumor immune response have been found to show therapeutic efficacy in the treatment of various cancers. This past year, for instance, the PD-1 agent pembrolizumab (MK-3475) was found to contribute to a 1-year survival rate of $69 \%$ in metastatic melanoma patients with prior systematic therapies of ipilimumab, leading to its FDA approval for use in second-line settings [11]. In a separate PD-1 inhibitor trial, the monoclonal antibody nivolumab (used in combination with ipilimumab) was found to produce a 1 -year $85 \%$ survival rate and 2 -year $79 \%$ survival rate in advanced melanoma patients [12]. In another phase 1 study, this time on patients with metastatic renal cell carcinoma, nivolumab and ipilimumab were found to contribute to a response rate of $43 \%(\mathrm{~N} 3+\mathrm{I} 1$ arm; nivolumab at $3 \mathrm{mg} / \mathrm{kg}$ and ipilimumab at $1 \mathrm{mg} / \mathrm{kg}$ ) and $48 \%$. ( $11+\mathrm{I} 3 \mathrm{arm}$; nivolumab at $1 \mathrm{mg} / \mathrm{kg}$ and ipilimumab at $3 \mathrm{mg} / \mathrm{kg}$ ). The aforementioned study's results were encouraging, for the $\mathrm{N} 3+\mathrm{I} 1$ arm was found to have a median progression-free survival of 36.6 weeks, whereas the $\mathrm{N} 1+\mathrm{I} 3$ arm had a median progression free survival of 38.3 weeks [13].

Mirroring their efficacy in treating melanoma, PD-1 inhibitors have also been found to be potent agents in the treatment of RCC. Given that the PD-L1 ligand has been found to be correlated with poor mRCC prognosis, a number of PD-1 inhibitors (nivolumab, lambrolizumab, ZBMS-936559, MPDL3280A, AMP-224) are currently being investigated for their therapeutic efficacy [14]. In addition to its demonstrated therapeutic activity in treating melanoma, nivolumab has been found to have significant benefits in the treatment of mRCC. In a phase II study of nivolumab's activity in clear-cell mRCC patients pretreated with anti-VEGR agents presented in ASCO 2014 annual meeting, researchers examined doseresponse relationships, overall survival, objective response rate, and drug safety [15]. Patients were randomized and 
blinded to receive nivolumab at three different doses: at $0.3 \mathrm{mg} / \mathrm{kg}, 2 \mathrm{mg} / \mathrm{kg}$, or $10 \mathrm{mg} / \mathrm{kg}$. Although no dose-response relationship for progression-free survival (PFS) was found, significant anti-tumor activity was observed with the usage of nivolumab, including objective responses of relatively long duration. While the $0.3 \mathrm{mg} / \mathrm{kg}$ group had an overall survival (OS) of 18.2 months, median OS were not reached for other groups. Across doses, 19 out of 35 responders (54\%) had objective responses lasting greater than 12-20+ months. Overall, nivolumab was considered to be well-tolerated, for less than $17 \%$ of patients (across all doses) experienced grade 3-4 adverse events [15].

Despite its demonstrated activity, there is limited biomarker data to predict the therapeutic effect provided by nivolumab in treating clear-cell mRCC. A recent study presented in ASCO 2014 annual meeting, however, has provided valuable insight on the molecular mechanisms underlying nivolumab's activity by examining the serum of mRCC patients treated with nivolumab for chemokines and $\mathrm{T}$ cell infiltrates at baseline, day 8 of cycle 2 (biopsy), and day 2 of cycle 1 (serum) [16]. Employing a phase I open-label study design with four parallel treatment arms (1-3 for patients with previously treated mRCC, arm 4 for treatment-naive nRCC patients), the Choueiri et al. research team accumulated data on overall response rate, safety/tolerability, and treatment-induced changes in PD-L1 expression. Evidenced by increases in interferon-gamma signaling, T-cell tumor infiltrates in biopsies, and serum concentrations of CXCL9 and CXCL10, nivolumab was found to have significant clinical activity in 91 patients with both $\mathrm{mRCC}$ previously treated with TKIs and treatment-naive mRCC. The researchers observed an increase in immune activity for both serum chemokines CXCL9 (191\%) and CXCL10 (90\%), as well as an increase in $\mathrm{T}$ cell infiltrates by $70 \%(\mathrm{CD} 3+)$ and $88 \%$ (CD8+). Changes in biomarkers were consistent with PD-1 inhibition and provided evidence of immunomodulatory effects in serum and in the tumor microenvironment. The objective response rate was $16 \%$ (16\% in previously treated patients; $13 \%$ in untreated patients), and the median duration of response was 15 months. Responses were numerically higher in $\mathrm{PD}-\mathrm{L}^{+}$patients but were also seen in $\mathrm{PD}-\mathrm{L}^{-}$patients. The promising results of the Choueiri et al. trial will hopefully pave the way for future biomarker-based studies that examine links between therapeutic doses and the molecular activity of biological agents implicated in pharmacodynamics and cancer cell function.

\section{Targeted therapy for non-clear cell RCC}

While the RCC therapies discussed above were for the treatment of clear-cell renal cell carcinoma, the optimal systemic therapy for non-clear cell renal cell carcinoma remains a topic of debate among clinicians. While the most common histological classification among nccRCCs is papillary renal cell carcinoma (10-15\%), other histologies include chromophobes (5-10\%), oncocytomas, renal medullary carcinomas, collecting-duct carcinomas, sarcomatoid, and unclassified nccRCCs. Given that VHL mutations do not play a role in the non-clear cell renal carcinoma disease course, it is unclear whether antiangiogenic TKIs targeting VEGF-a standard of care in the treatment of clear-cell RCC-would have a therapeutic benefit to $\mathrm{mRCC}$ patients. In addition, the relative rarity of non-clear cell RCC in comparison to ccRCC poses a challenge to clinical researchers seeking to gain insights on a possible link between TKIs and non-clear cell RCC pathogenesis.

Despite these challenges, researchers have begun examining the novel application of VEGFR TKIs in the treatment of non-clear cell RCC and have found evidence suggestive that VEGF TKIs have therapeutic value in the treatment of nccRCC. Two drugs in particular, sunitinib and the mTOR inhibitor everolimus, have been investigated for their possible treatment benefits in nccRCC patients. In 2007, sunitinib, the aforementioned orally administered inhibitor of tyrosine kinases ranging from VEGFRs to PDGFRs, was found to contribute to significantly higher progression-free survival and response rate in mRCC patients participating in a phase III trial [17]. In the following year, another phase III trial led by the Motzer et al. group revealed that everolimus prolonged progression-free survival compared to placebo in a sample of mRCC patients after sorafenib and/or sunitinib treatment [18].

In a randomized phase 2 trial of non-clear cell RCC presented in the 2014 ASCO annual meeting (the ESPN trial), researchers sought to evaluate the assumption that mTOR inhibitors like everolimus may benefit "poor-risk" disease patients such as those with nccRCC in terms of improved progression-free survival and overall survival. Employing a crossover study design, researchers evaluated the premise that median PFS would be improved from 12 weeks with sunitinib to 20 weeks with everolimus. Amid a sample of 68 participants (27 papillary, 11 chromophobe, 9 unclassified, 7 translocated, 13 sarcomatoid, 1 oncocytic), researchers noted significantly higher overall survival in the sunitinib arm (not reached vs 10.5 months, $\mathrm{p}=0.01$ ). Chromophobe histology was also found to have better overall survival and progression-free survival than other histologies in both arms [19].

Because of the superior overall survival among participants taking sunitinib, the ESPN study was prematurely terminated as recommended by data and safety monitoring committee; differences in progression-free survival were consequently not observed in the first-line between sunitinib (6.1 months) and everolimus (4.1 months, $\mathrm{p}=0.6$ ). Following cross-over, the progression-free survival in the second line was relatively 
short: 1.8 months for sunitinib and 2.8 months for everolimus $(p=0.6)$. Based on futility analysis for progressionfree survival and inferior overall survival with everolimus compared to sunitinib in the first-line setting, termination of further patient accrual was recommended for the trial, and consequently everolimus was not recommended as a first-line treatment option in nccRCC. It warrants emphasis that everolimus does not target mTOR complex 2, which has been identified as a powerful driver of tumor proliferation [20]. Given that the targeting of mTOR-2 could potentially contribute to RCC treatment benefits, future research is needed on the efficacy of therapies that target components of the mTOR signaling besides solely mTOR-1.

\section{Conclusions}

In summary, the metastatic ccRCC treatment landscapepreviously dominated by targeted therapies-could be altered significantly with the advent of potent immunotherapies that abrogate the PD-1 pathway. However, targeted therapies such as TKIs continue to hold much promise in the management of clear cell and nccRCC. Future randomizedcontrolled studies are needed in order to determine if new PD-1 inhibitors or their combination with TKIs may provide survival benefits in the treatment of RCC.

\section{Abbreviations \\ BM: Bone metastases; ccRCC: Clear cell renal cell carcinoma; HIF1-a: Hypoxia-inducible factor 1-alpha; mRCC: Metastatic renal cell carcinoma; mTOR: Mammalian target of rapamycin; nccRCC: Non-clear cell renal cell carcinoma; OS: Overall survival; PD-1: Programmed death-1; PDGFR: Platelet-derived growth factor receptor; PFS: Progression-free survival; RCC: Renal cell carcinoma; RCT: Randomized controlled trial; TKI: Tyrosine kinase inhibitor; VEGF: Vascular endothelial growth factor; VHL: Van-Hippel lindau.}

\section{Competing interests}

SW is a speaker for Astella-Medivation, Pfizer and Novartis. No financial support was provided for this study.

\section{Authors' contributions}

Both authors have contributed to literature review, drafting, and revising of the manuscripts. KYX wrote the first draft of manuscript and developed the arguments for the paper. KYX and SW contributed to the revision of the manuscript, agreed with interpretations, and approved the final version of the manuscript. Both authors read and approved the final manuscript.

\section{Acknowledgments}

SW is supported by the Research Foundation of the State University of New York (SUNY).

\section{Author details \\ 'Department of Medical Education, Icahn School of Medicine at Mount Sinai, New York, NY, USA. ${ }^{2}$ Division of Hematology/Oncology, Department of Medicine, Stony Brook University School of Medicine, Room: HSC 15-053E, Stony Brook, NY, USA. ${ }^{3}$ Northport VA Medical Center, Northport, NY, USA.}

Received: 23 December 2014 Accepted: 2 February 2015

Published online: 02 March 2015

\section{References}

1. Siegel R, Naishadham D, Jemal A. Cancer statistics, 2012. CA Cancer J Clin. 2012;62:10-29.
2. Cowey $\mathrm{CL}$, Rathmell WK. VHL gene mutations in renal cell carcinoma: role as a biomarker of disease outcome and drug efficacy. Curr Oncol Rep. 2009;11:94-101.

3. Logan JE, Rampersaud EN, Sonn GA, Chamie K, Belldegrun AS, Pantuck AJ, et al. Systemic therapy for metastatic renal cell carcinoma: a review and update. Rev Urol. 2012;14:65-78.

4. Thompson Coon J, Hoyle M, Green C, Liu Z, Welch K, Moxham T, et al. Bevacizumab, sorafenib tosylate, sunitinib and temsirolimus for renal cell carcinoma: a systematic review and economic evaluation. Health Technol Assess. 2010;14:1-184.

5. Escudier B, Pluzanska A, Koralewski P, Ravaud A, Bracarda S, Szczylik C, et al. Bevacizumab plus interferon alfa-2a for treatment of metastatic renal cell carcinoma: a randomised, double-blind phase III trial. Lancet. 2007;370:2103-11.

6. Sternberg CN, Davis ID, Mardiak J, Szczylik C, Lee E, Wagstaff J, et al. Pazopanib in locally advanced or metastatic renal cell carcinoma: results of a randomized phase III trial. J Clin Oncol. 2010;28:1061-8.

7. Escudier B, Eisen T, Stadler WM, Szczylik C, Oudard S, Siebels M, et al. Sorafenib in advanced clear-cell renal-cell carcinoma. N Engl J Med. 2007;356:125-34

8. Rini Bl, Escudier B, Tomczak P, Kaprin A, Szczylik C, Hutson TE, et al. Comparative effectiveness of axitinib versus sorafenib in advanced renal cell carcinoma (AXIS): a randomised phase 3 trial. Lancet. 2011;378:1931-9.

9. Hudes G, Carducci M, Tomczak P, Dutcher J, Figlin R, Kapoor A, et al. Temsirolimus, interferon alfa, or both for advanced renal-cell carcinoma. N Engl J Med. 2007;356:2271-81.

10. Kalra S, Verma J, Atkinson BJ, Matin SF, Wood CG, Karam JA, et al. Outcomes of patients with metastatic renal cell carcinoma and bone metastases in the targeted-therapy era. In: Book Outcomes of patients with metastatic renal cell carcinoma and bone metastases in the targeted-therapy era (Editor ed. $\wedge$ eds.). City: 2014 Genitourinary Cancers Symposium; 2014.

11. Ribas A, Hodi FS, Kefford R, Hamid O, Daud A, Wolchok JD, et al. Immunomodulatory activity of nivolumab in previously treated and untreated metastatic renal cell carcinoma (mRCC): Biomarker-based results from a randomized clinical trial. In: Book Immunomodulatory activity of nivolumab in previously treated and untreated metastatic renal cell carcinoma (mRCC): Biomarker-based results from a randomized clinical trial. (Editor ed.^eds.). City: ASCO Annual Meeting; 2014.

12. Sznol M, Kluger HM, Callahan MK, Postow MA, Gordon RA, Segal NH, et al. Survival, response duration, and activity by BRAF mutation status of nivolumab (NIVO, anti-PD-1, BMS-936558, ONO-4538) and ipilimumab concurrent therapy in advanced melanoma. In: Book Survival, response duration, and activity by BRAF mutation status of nivolumab (NIVO, anti-PD-1, BMS-936558, ONO-4538) and ipilimumab concurrent therapy in advanced melanoma (Editor ed. $\wedge$ eds.). City: ASCO Annual Meeting; 2014.

13. Hammers HJ, Plimack ER, Infante JR, Ernstoff MS, Rini BI, McDermott D, et al. Phase I study of nivolumab in combination with ipilimumab in metastatic renal cell carcinoma (mRCC). In: Book Phase I study of nivolumab in combination with ipilimumab in metastatic renal cell carcinoma (mRCC). (Editor ed.^eds.). City: American Society of Clinical Oncology (ASCO); 2014.

14. Gunturi A, McDermott DF. Potential of new therapies like anti-PD1 in kidney cancer. Curr Treat Options Oncol. 2014;15:137-46.

15. Motzer RJ, Rini BI, McDermott DF, Redman BG, Kuzel T, Harrison MR, et al. Nivolumab for metastatic renal cell carcinoma (mRCC): Results of a randomized, dose-ranging phase trial. In: Book Nivolumab for metastatic renal cell carcinoma (mRCC): Results of a randomized, dose-ranging phase trial (Editor ed.^eds.). City: ASCO Annual Meeting; 2014

16. Choueiri TK, Fishman MN, Escudier B, Kim JJ, Kluger HM, Stadler WM, et al. Immunomodulatory activity of nivolumab in previously treated and untreated metastatic renal cell carcinoma (mRCC): Biomarker-based results from a randomized clinical trial. In: Book Immunomodulatory activity of nivolumab in previously treated and untreated metastatic renal cell carcinoma (mRCC): Biomarker-based results from a randomized clinical trial (Editor ed.^eds.). City: ASCO Annual Meeting; 2014.

17. Motzer RJ, Hutson TE, Tomczak P, Michaelson MD, Bukowski RM, Rixe O, et al. Sunitinib versus interferon alfa in metastatic renal-cell carcinoma. N Engl J Med. 2007;356:115-24.

18. Motzer RJ, Escudier B, Oudard S, Hutson TE, Porta C, Bracarda S, et al. Efficacy of everolimus in advanced renal cell carcinoma: a double-blind, randomised, placebo-controlled phase III trial. Lancet. 2008;372:449-56. 
19. Tannir NM, Jonasch E, Altinmakas E, Ng CS, Qiao W, Tamboli P, et al.

Everolimus versus sunitinib prospective evaluation in metastatic non-clear cell renal cell carcinoma (The ESPN Trial): a multicenter randomized phase 2 trial. In: Book Everolimus versus sunitinib prospective evaluation in metastatic non-clear cell renal cell carcinoma (The ESPN Trial): A multicenter randomized phase 2 trial (Editor ed.^eds.). City: ASCO Annual Meeting; 2014.

20. Hudes GR. Targeting mTOR in renal cell carcinoma. Cancer. 2009;115:2313-20

Submit your next manuscript to BioMed Central and take full advantage of:

- Convenient online submission

- Thorough peer review

- No space constraints or color figure charges

- Immediate publication on acceptance

- Inclusion in PubMed, CAS, Scopus and Google Scholar

- Research which is freely available for redistribution 